fixation point, or the margins of a hemianopia and the like. If one merely determines the limits of the field by moving the object radially-in contra-distinction to rotatorily-at, say, intervals of even $15^{\circ}$, one does not obtain accurate results and one cannot plot out hemianopias and fields with deep re-entering angles with certainty.

As at present constructed, it is difficult to employ the Elliot scotometer except by rotating it. The result is that one obtains a very "spikey" diagram. These spikes largely disappear when the same field is worked out on a Bjerrum screen, the angles becoming rounded off as the result of taking further observations to one side and the other of the spike.

In taking a field out with a Bjerrum screen, the object can be moved in any direction. With a perimeter, it can only be moved in two, radially and rotatorily. With an Elliot it can only be rotated.

The most accurate field is most easily taken out with a Bjerrum screen, but with care an equally accurate field can be obtained with a perimeter. It requires great care to produce a chart with an Elliot that does not give the impression that the true scotoma of the disc may not be exactly the shape that is depicted.

\title{
Fatigue of Patient
}

Care should be taken not to fatigue the patient. If fatigued his attention will wander and inaccurate records will result, and the time both of the surgeon and the patient will be wasted.

\section{THE THEORY OF COLOUR VISION}

BY

F. W. EdRIDGe-Green, C.B.E., LONDON.

Concluded from p. 412.

$$
\text { ' }
$$

Mr. Parsons now passes to the subject of colour vision.

\section{III.-Colour Names}

Mr. Parsons does not seem to have comprehended my view with regard to colour names though he has conceded the point for which I fought for so many years, namely, the use of colour names in a practical test for colour blindness. No one has opposed me more strongly on this point than Mr. Parsons; in fact, in the second edition of his book, 1912, he writes: "The fundamental axiom in 
colour testing is that no importance should be attached to the naming of colours." This point has now been universally settled and tests which were previously constructed as non-naming tests have been made into naming tests. The use of colour names in a scientific method of classification is important, but from another aspect. When a man is examined with my spectrometer we have a key to his colour vision. A man, for instance, who has a neutral point in the spectrum is definitely dichromic irrespective of the result of further tests. Though he may try to name different portions of the spectrum he will generally state that there are only two colours. In the same way a trichromic is diagnosed by the description of the spectrum as red, redgreen, green, green-violet, and violet. The names given to colours by these men are quite characteristic, and show that in the dichromic there are only two colour sensations, and with the trichromic only three. I have often given demonstrations to show that the colour naming of the colour-blind is not haphazard nor dependent only on luminosity. I have stated before the demonstration that I would give a signal before asking the question to indicate whether the reply to my question would be correct or not. It is obvious that, in making a classification of any kind, this must be done with intelligence and discrimination. Some men are good observers and others are not, but it must not be concluded from this that a good observer has better colour vision than the bad observer.

\section{IV.-Discrimination of Hue}

My colour perception spectrometer was designed entirely for the detection and classification of colour-blindness. It is possible that a method may be designed which will enable the normal sighted to distinguish more differences of hue, but all the objections which I have raised to former methods must be eliminated. I gave a demonstration in which the monochromatic divisions of the spectrum were with the aid of a double image prism projected upon a screen at a meeting of the Dutch Association for Science at Groningen. The duplicated monochromatic divisions appeared as large rectangular patches of light upon the screen, the red side of one touching the violet side of the other, but even then with the aid of simultaneous colour contrast no one in the audience was able to say which was the red side and which was the violet side of the monochromatic division shown. If, however, the luminosity of one of the patches were diminished, a difference of hue was at once observable. It should here be pointed out that $1.5 \mu \mu$ is given by Dr. Watson as the least perceptible difference of hue in the region of the D. lines. The first $\mathrm{D}$. line is $589.6 \mu \mu$ and the second 
$589 \mu \mu$, so that it would require a better discrimination than $1.5 \mu \mu$ to discriminate between them. When two adjacent portions of spectrum are being compared for the least perceptible difference of hue, the divisions must be of equal luminosity, of equal dispersion (therefore, the prisms should be cut from the same piece of glass), the lenses should be exactly the same, the images must just touch and fall on similar portions of the retina, that is, one must not be on the yellow spot and the other on an adjacent region, the angle should be as nearly as possible the same and white or coloured stray light should not be mixed with one of the divisions. The spectrometer when used with a double image prism fulfils all these conditions.

Mr. Parsons refers to a case of mine, a dichromic, who was examined by Dr. Watson. This was a man to whom I referred as having a sense of luminosity similar to the normal, and numerous other observers have made the same statement with regard to dichromic cases. I examined the man in three ways:- First he made a series of matches which were exactly similar to mine. Secondly, his ratio of red and green was tested with a flicker photometer and was exactly the same as mine. Thirdly, Prof. A. W. Porter and I tested him with spectral green light as to the exact point of disappearance when reduced in luminosity; this was exactly the same as ours. It is, therefore, quite evident that this man did not possess any defect in the luminosity of the green. When I saw him examined by. Dr. Watson, I at once saw the defect in the latter's methods, which must vitiate all his results. Dr. Watson combined with the flicker photometer, green and white. Now in the dichromic, green and white are much more similar than in the normal sighted and, therefore, the difference seen by a normal sighted person is not obvious to the dichromic, a striking flicker appearing to the normal sighted when the two have combined to the dichromic. For several years I used the flicker photometer and found it absolutely necessary to compare two colours directly; when there is a defect, as, for instance, shortening of the red end of the spectrum, the change in the ratio is striking. A man may become totally colour blind and yet have no defect in form vision or luminosity. I examined a signalman who became totally colour blind after tetanus and whose form vision was perfect.

Mr. Parsons states that Burch pointed out the fallacies of Professor A. W. Porter's and my experiments on successive contrast. This should have been expressed differently, namely, that Burch found with his own eyes a different result. I have the highest opinion of Burch's work and have no doubt that he saw the phenomenon as described by him, but I have conclusive evidence that others when making observations similar to his did not see as he did. It is probable that his eyes were abnormal and I know. 
that he damaged them with the strong light that he used. In this way he may have damaged his yellow sensation. All his results are explicable on the assumption that he had only four colour sensations : red, green, blue, and violet. I had one patient, the late Adam Hilger, the spectroscope maker, who became an extreme dichromic with his right eye through prolonged work on the colours of the spectrum with this eye. He saw the spectrum as a white band with a tinge of red at one end of the spectrum and a tinge of violet at the other. His form vision was not affected; in fact he found he could pick out the fine lines of the spectrum much more easily with this eye than the other. There is probably no single set of experiments which has given me more converts than those of Porter's and mine on successive contrast. The experiments extended over months and numerous people were examined, many from other laboratories who were prejudiced by other views. Their observations were taken without bias and agreed with ours. We mentioned in our paper a small amount of stray light simply as a matter of minute accuracy but the results were the same when this was excluded. This is expressly stated in my book. p. 251. It is this stray light, but in much larger quantity, which has caused the results of other observers. For instance, a red with an addition of a small amount of stray light will become more saturated after fatigue to green but not when there is no stray light. On this point Burch agrees with us.

Mr. Parsons alludes to my experiments on the movements of after-images; the facts are quite easy to observe, but I quite agree with him that it is extremely unlikely that the movement of the head actually moves the fluid by gravity. I believe that this is done by the accompanying movements of the muscles of the eye expressing the fluid in different directions. This view is supported by the fact that a blue-green after-image may go right through a red one. The movement, however, appears to correspond to the direction of movement. For instance, repeating this a few days ago with a round positive after-image, on moving my head sharply downwards the after-image appeared to move upwards and split into two portions, a distorted semi-circle and a split triangle, with an interval between them. On then moving my head sharply to the right a long streak appeared to the left.

Mr. Parsons has alluded to the different varieties of colour blindness which I have described; these are dealt with fully in my book. I have never met with a case of colour blindness which could be explained on the older theories when examined in minute detail. As an example, I will take a case which at first sight appeared one of typical red blindness, that is, a dichromic with a shortening of the red end of the spectrum. This man could make matches with Lord Rayleigh's colour-mixing apparatus, that is, 
mixing red and green to match yellow. He not only made the normal equation, but in a series of obsiervations showed less mean deviation than any normal sighted person I have examined. I was a month in Freiburg in order to see von Kries's methods. I told him of this case; his reply was: "Such a case is absolutely impossible ; it would upset all our views." As the man happened to be in Freiburg at the time, I took him to von Kries, who examined him. von Kries, after an hour's examination, remarked : "How can you say this man is colour blind; he is absolutely normal." I then suggested that a match should be made between green and a mixture of ${ }^{\prime}$ red and violet. This he did, matching a brilliant purple against green. von Kries then said: "You don't call that much of a match, do you ?" His reply was: "Yes I do; it is the best match I have made this morning." von Kries then gave me a letter giving details of the examination, and agreeing with my view. In this case the shortening of the red end of the spectrum only affected colours containing rays from the shortened portion, and therefore the dichromatism could not have been caused by the absence of a red sensation. I have given this case in detail to show that it is absolutely necessary to see facts and methods before forming an opinion.

Mr. Parsons has accused me of adopting Rollet's theory of simultaneous contrast and not acknowledging the source. My theory is totally different from that of Rollet, with which I do not agree, neither can the facts be explained on the Young theory. Inhibition and subtraction are not synonymous terms. I find no evidence of inhibition. The crucial fact, which seems to have been entirely overlooked, is that the colour is subtracted from the so-called inducing colour, as well as from the grey.

In conclusion, what does Mr. Parsons's attack consist of ? Simply of statements that so and so obtains results different from EdridgeGreen, garnished with superlative adjectives to force his point. The cause of truth is not advanced by refusing to look at facts. Why is it that every other review of my book is so favourable when $\mathrm{Mr}$. Parsons has not a good word to say of any portion of it ? Let any reader compare the reviews in the Philosophical Magazine, Nature, or the Revue générale des Sciences, Paris. Professor Dufour, the writer of the last-named review, states: "Cette manière de voir se trouve en accord complet avec tous les faits connus de la vision des couleurs, et elle a permis à $\mathrm{M}$. Edridge-Green de prévoir des faits nouveaux qui n'étaient pas connus à l'époque où il édifiait cette théorie." 